\title{
LES DIEUX ET LES HOMMES
}


ÉCOLE DES HAUTES ÉTUDES EN SCIENCES SOCIALES

\section{CAHIERS DE L'HOMME \\ Etbnologie - Géograpbie - Linguistique \\ NOUVELLE SÉRIE XVIII}

MOUTON ÉDITEUR - PARIS - LA HAYE - NEW YORK MCMLXXIX 
MARIE-LOUISE REINICHE
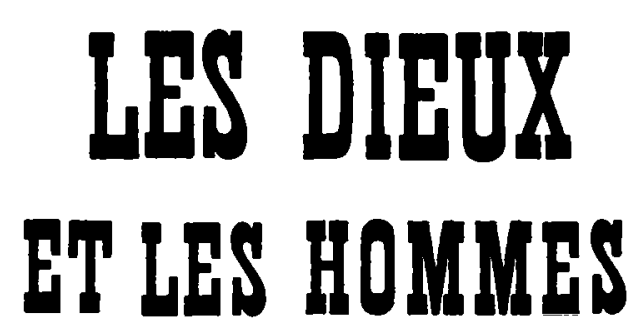

\section{Étude des cultes \\ d'un village du Tirunelveli \\ Inde du Sud}

MOUTON ÉDITEUR - PARIS - LA HAYE - NEW YORK MCMLXXIX 


\begin{abstract}
CET OUVRAGE A ETÉ PUBLIÉ AVEC LE CONCOURS DU CENTRE NATIONAL DE LA RECHERCHE SCIENTIFIQUE
\end{abstract}

ISBN : 2-7132-0690-1 (EHESS)

2-7193-0460-3 (Mouton)

(C) 1979 by Mouton Editeur and Ecole des Hautes Études en Sciences Sociales

Imprimé en France 